\title{
What Patients with Mild-to-Moderate Kidney Disease Know, Think, and Feel about Their Disease: An In-Depth Interview Study
}

\author{
Carola van Dipten, MD, Wim J.C. de Grauw, MD, PhD, Jack F.M. Wetzels, MD, PhD, \\ Willem J.J. Assendelft, MD, PhD, Nynke D. Scherpbier-de Haan, MD, PhD, and
}

Marianne K. Dees, $M D, P h D$

Introduction: It is unknown what patients in primary care with mild-to-moderate chronic kidney disease (CKD) know, think, and feel about their diagnoses and how they value the information provided. The aim of the study was to explore their knowledge, thoughts, and experiences concerning their CKD and the information given to them.

Method: Qualitative interview study with patients with mild-to-moderate CKD who know their diagnoses and are treated mainly by family physicians.

Results: Four themes arose: CKD literacy, coping with anxiety, prerequisites for self-management, and reciprocity in information provision. The participants filled deficiencies in their CKD knowledge with misconceptions and half-truth about causes, symptoms, and treatment. The anxiety about CKD at the time of diagnosis versus the feeling of irrelevance later on was due to the absence of CKD symptoms and their physicians' minimization of the seriousness of CKD. Participants failed to connect lifestyle and cardiovascular disease with CKD. Not all participants were well informed about the consequences that CKD might have. CKD literacy and willingness to change were both necessary to accept lifestyle changes. Further, the participants felt that it would be helpful when information comes with empathy and is tailored to patients' personal needs.

Conclusions: Patients have various perceptions about their CKD. Exploring these perceptions could help match their needs with better-tailored information. Doctors should be aware that they can deliver inaccurate signals about CKD severity, so that patients fail to realize the potential impact of CKD. This makes them less open to lifestyle changes and improving their self-management. (J Am Board Fam Med 2018;31:570-577.)

Keywords: Chronic Kidney Diseases, Family Physicians, Life Style, Primary Health Care, Qualitative Research, SelfManagement

Most patients with chronic kidney disease (CKD) in stages 1 to 3 are treated in primary care. ${ }^{1}$ The prevalence of $\mathrm{CKD}$ is $10 \%$ to $12 \%$ and is expected to increase due to aging and rising incidences of hypertension and diabetes. ${ }^{2}$ Nearly all interven-

This article was externally peer reviewed.

Submitted 13 December 2017; revised 29 March 2018; accepted 30 March 2018.

From Radboud Institute for Health Sciences, Department of Primary and Community Care, Radboud University Medical Center, Nijmegen, the Netherlands (CvD, WdG, WA, NS, MD); Radboud Institute for Health Sciences, Department of Nephrology, Radboud University Medical Center, Nijmegen, the Netherlands (JW).

Funding: The Dutch Kidney Foundation funded the study, grant $13 \mathrm{~A} 4 \mathrm{D} 302$. tions for patients with CKD in primary care aim to prevent cardiovascular complications and progression to end-stage renal disease. Not only the treatment of hypertension and diabetes, but also lifestyle changes such as smoking cessation, exercise, weight loss, low salt intake, and medication management are important. These measures rely extensively on patient self-management. The prerequi-

Conflict of interest: none declared.

Corresponding author: Carola van Dipten, MD, Department of Primary and Community Care, Radboud University Medical Center, Postal Route 117, P.O. Box 9101, 6500 HB Nijmegen, the Netherlands (E-mail: Carola.vanDipten@ radboudumc.nl). 
sites for self-management are patient awareness of the diagnosis and education, and the firm belief that the patient's role and willingness to make lifestyle changes is important. ${ }^{3}$ Tailored education in primary care is the key to achieving self-management. However, previous research shows that family physicians and practice nurses encounter barriers when informing patients about the diagnosis of $\mathrm{CKD},{ }^{4}$ and quantitative studies confirm the low awareness of the diagnosis among patients with mild-to-moderate CKD. ${ }^{5,6}$ Patients have little specific knowledge about causes, kidney function, treatment, and nephrotoxic medication. ${ }^{7,8}$ Despite research into the information and educational needs of patients with severe $\mathrm{CKD}$, research relating to patients with mild-to-moderate CKD is scarce. ${ }^{9,10}$ To enhance self-management and knowledge, we must first explore what patients know, think, and feel about their disease and about the provided information. Therefore, the aim of this study was to explore patients' knowledge, thoughts, and feelings about CKD, as well as their experiences with the information provision for patients with mild-to-moderate $\mathrm{CKD}$ in primary care.

\section{Method \\ Study Design}

We conducted in-depth interviews with patients with CKD. We considered this design appropriate for our exploratory research question. We used the consolidated criteria for reporting qualitative health research checklist as a reporting structure. ${ }^{11}$

\section{Participant Selection}

Physicians from 8 practices, associated with the primary care network of practice-based research in Nijmegen, the Netherlands ${ }^{12,13}$, recruited patients by phone or e-mail, based on recent consultation or on a sampling from the problem lists, pointing at kidney failure. The inclusion criteria were CKD stages 1 to 3, being informed about the CKD diagnosis, speaking the Dutch language, and CKD management based mainly in primary care. We used a purposive strategy for sampling. After the first 10 patients, we asked the physicians to recruit patients with specific characteristics, characteristics that were not yet represented in the participants who had already been interviewed. We aimed for variety in the categories: age, sex, CKD cause, estimated glomerular filtration rate, duration of the diagnosis, and education level. The participant sampling, data collection, and analysis were organized in an iterative process. The physicians asked 25 patients to participate. Two patients were excluded because they had been diagnosed with severe CKD (stages 4 and 5). One married couple was recruited. We decided to interview only 1 of them because they likely shared the same knowledge and ideas. One patient refused to participate because he felt misinformed about the type of research. The study population comprised 21 patients (see Table 1 for participants characteristics). Patients were first informed by their family physician by a letter. Further information was provided by the researcher $(\mathrm{CvD})$ before the participants signed for informed consent. The interviews were conducted between December 2015 and August 2016.

\section{Data Collection}

We developed an interview guide (Appendix A) based on the literature. This interview guide was pilot-tested on 2 participants who were members of the Dutch Kidney Patient Association. The guide was adjusted after each 3 to 7 interviews, with the use of new insights from the previous interviews and discussion in the research team (for adjustments, see Appendix A). The interviews with the participants took place at their homes or in the practices. The interviewer was an $\mathrm{MD}$ and $\mathrm{PhD}$ student and trained in qualitative research $(\mathrm{CvD}$, female). She had no connection with the participants. The interviews lasted 30 to 80 minutes. All interviews were audiotaped and transcribed verbatim. The transcripts were returned to the participants for a member check. Three participants reported corrections in the transcripts: 2 nuanced their statements and 1 reported grammatical errors. The analysis of the 21 st interview produced no new codes or concepts. We concluded that saturation had been reached.

\section{Data Analysis}

We used the technique of constant comparative analysis. This approach is part of the grounded theory in which concepts emerge as theory is formed. ${ }^{14}$ Analysis started after the first interview. The analysts $(\mathrm{CvD}$ and $\mathrm{MD}$ ) coded inductively and independently by using Atlas.ti (version 7.1.5). They discussed, merged, and renamed codes after the 3rd, 10th, 16th, and 21st interviews. CD and MD sorted the preliminary findings into categories and themes. The codes, 
Table 1. Demographic Information about the Participants

\begin{tabular}{|c|c|c|c|c|c|c|c|c|}
\hline $\begin{array}{l}\text { Participant } \\
\text { Number }\end{array}$ & Sex & Age & $\begin{array}{l}\text { Marital } \\
\text { Status }\end{array}$ & $\begin{array}{l}\text { Level of } \\
\text { Education }\end{array}$ & $\begin{array}{l}\text { CKD } \\
\text { Since }\end{array}$ & eGFR & Albuminuria & Comorbidity \\
\hline 1 & M & 71 & Married & Middle & 1995 & 48 & No & Hypertension, gout \\
\hline 2 & $\mathrm{~F}$ & 64 & Married & Middle & 2010 & 43 & No & $\begin{array}{l}\text { Hypertension, } \\
\text { adiposity, } \\
\text { hypothyroidism }\end{array}$ \\
\hline 3 & $\mathrm{~F}$ & 66 & Married & Low & 2015 & 54 & Not measured & $\begin{array}{l}\text { Hypertension, } \\
\text { psoriasis, arthrosis }\end{array}$ \\
\hline 4 & M & 75 & Partners & Low & 2011 & 48 & Microalbuminuria & $\begin{array}{l}\text { Hypertension, diabetes, } \\
\text { gout, CVA, angina } \\
\text { pectoris }\end{array}$ \\
\hline 5 & M & 73 & Married & Middle & 2014 & 43 & Not measured & Hypertension, arthrosis \\
\hline 6 & $\mathrm{~F}$ & 66 & Widow & High & 2006 & 48 & Microalbuminuria & Hypertension \\
\hline 7 & \multicolumn{8}{|c|}{ Did not meet the entry criteria } \\
\hline 8 & \multicolumn{8}{|c|}{ Did not meet the entry criteria } \\
\hline 9 & $\mathrm{~F}$ & 62 & Divorced & High & Unknown & 45 & Not measured & Hypertension, arthrosis \\
\hline 10 & $\mathrm{~F}$ & 41 & Divorced & Middle & 1992 & 56 & Microalbuminuria & $\begin{array}{l}\text { Nephrectomy, } \\
\text { recurrent cystitis }\end{array}$ \\
\hline 11 & $\mathrm{~F}$ & 86 & Widow & High & Unknown & 55 & Microalbuminuria & $\begin{array}{l}\text { Hypertension, } \\
\text { arthrosis, deep vein } \\
\text { thrombosis }\end{array}$ \\
\hline 12 & \multicolumn{8}{|c|}{ Felt misinformed about the type of research and quit } \\
\hline 13 & M & 62 & Married & High & 2011 & 38 & Microalbuminuria & $\begin{array}{l}\text { Hypertension, diabetes, } \\
\text { CVA, gout, } \\
\text { polyneuropathy }\end{array}$ \\
\hline 14 & $\mathrm{~F}$ & 76 & Married & Middle & 1996 & 46 & No & $\begin{array}{l}\text { Diabetes, CVA, } \\
\text { endometrial cancer }\end{array}$ \\
\hline 15 & \multicolumn{8}{|c|}{ Married to another participant; excluded because of same ideas } \\
\hline 16 & $\mathrm{~F}$ & 78 & Married & High & 2014 & 47 & Microalbuminuria & $\begin{array}{l}\text { Hypertension, } \\
\text { hypercholesterolemia }\end{array}$ \\
\hline 17 & M & 64 & Partners & Low & 1995 & 45 & Macroalbuminuria & $\begin{array}{l}\text { Hypertension, aortic } \\
\text { insufficiency }\end{array}$ \\
\hline 18 & $\mathrm{~F}$ & 78 & Widow & Middle & 2012 & 46 & No & $\begin{array}{l}\text { Hypertension, } \\
\text { hypercholesterolemia }\end{array}$ \\
\hline 19 & $\mathrm{~F}$ & 65 & Married & Low & 2013 & 48 & Microalbuminuria & $\begin{array}{l}\text { Asthma, ileostomy for } \\
\text { constipation }\end{array}$ \\
\hline 20 & M & 71 & Married & High & 2012 & 47 & No & $\begin{array}{l}\text { Hypertension, prostate } \\
\text { cancer }\end{array}$ \\
\hline 21 & $\mathrm{~F}$ & 56 & Married & Middle & Unknown & 50 & Microalbuminuria & $\begin{array}{l}\text { Asthma, osteoporosis, } \\
\text { rheumatoid arthritis }\end{array}$ \\
\hline 22 & M & 76 & Married & High & 2009 & 39 & Not measured & $\begin{array}{l}\text { Hypertension, bladder } \\
\text { cancer }\end{array}$ \\
\hline 23 & $\mathrm{M}$ & 64 & Married & Middle & 2013 & 41 & Microalbuminuria & Hypertension \\
\hline 24 & $\mathrm{~F}$ & 62 & Unknown & Unknown & Unknown & 51 & Microalbuminuria & $\begin{array}{l}\text { Hypertension, } \\
\text { hypercholesterolemia }\end{array}$ \\
\hline 25 & $\mathrm{~F}$ & 73 & Married & Low & Unknown & 53 & No & $\begin{array}{l}\text { Hypertension, diabetes, } \\
\text { asthma }\end{array}$ \\
\hline
\end{tabular}

CKD, chronic kidney disease; CVA, cardiovascular accident; eGFR, estimated glomerular filtration rate

categories, and themes were constantly compared with the transcripts. ${ }^{15}$ After saturation, the research team (CvD, MD, WdG, and NS) discussed all codes, categories, and themes. Five consensus meetings were needed to construct the final thematic map (Appendix B). A native-English speaker translated the illustrative quotes.

\section{Results}

\section{Overview}

Four main themes emerged from the interviews: CKD literacy, coping with anxiety, prerequisites for self-management, and reciprocity in information provision. All themes are illustrated by multiple categories and quotes. 


\section{CKD Literacy}

We found that patients complete their knowledge gaps with misconceptions, half-truths, and distortion of facts to create their own image about CKD and all what comes with CKD.

\section{Imagining CKD}

The information obtained from the interviews showed that CKD is an unclear concept. A broad spectrum of ideas and views appeared when the interviewees were asked for a definition: a shriveled kidney, a number in the computer, blood poisoning, or a shortage of blood substances.

“... that I had a kidney that you could compare with a pottery cup with all kinds of cracks in it. Say just an old cup. That is what my kidney was like." (participant $5[\mathrm{P} 5])$

\section{Knowledge Compatible with Professional Standards}

Knowledge that corresponded with professional knowledge varied among the interviewed patients. Most patients knew that the kidneys are located in the abdomen and have something to do with the purification of blood. It was less commonly known that CKD is associated with cardiovascular disease. A variety of CKD causes were mentioned: aging, medication, dehydration, and chemotherapy, but despite that, most participants did not link CKD to their hypertension or diabetes. If they knew hypertension or diabetes causes CKD, it was still difficult to imagine how CKD related to vascular damage.

"But at my doctor's, there was the idea that high blood pressure has an influence, that high blood pressure attacks the organs." (P6)

The participants rightly linked CKD to pregnancy issues, gout, and problems with contrast agents. Fatigue and itch were mentioned as symptoms. Others experienced no symptoms or were not sure whether their symptoms were related to CKD. It was clear that CKD needs periodic followup, including blood and urine examination, to monitor kidney function. Treatment was mainly associated with taking medication. It proved difficult to say which drugs are involved in CKD management and what the effects of the medication should be. However, there was an awareness of medication warnings in case of renal impairment, for example, for nonsteroidal anti-inflammatory drugs, gout medication, and antihypertensive agents.

\section{Misconceptions}

Many misconceptions came forward, probably as a result of lack of knowledge. Could kidney damage be caused by stress, narcosis, car accidents, viruses, and bacteria, or was it a side-effect of psoriasis?

"I have an idea that it has something to do with this." (Points to a psoriasis spot) (P3)

Another source of misconception was speculation about symptoms. Pain, edema, myalgia, infections, and urinary symptoms were considered symptoms of CKD.

"Yes, I know that it can be very painful if something's wrong with your kidneys; my father had that too. And then it is difficult to urinate, and so on." (P14)

There were various thoughts about diagnostics. There was the conviction that CKD can only be made visible by a body scan, because a scan was made at diagnosis. Furthermore, there was the idea that the color of the urine reflects health.

"You can see your health in your urine. You just see it yourself - then you have much darker urine." (P6)

It was reported that cinnamon affects CKD positively. Others were convinced that CKD does not require treatment at all. The patients did not always realize that CKD is a life-long illness, and they thought that CKD was curable.

\section{Gray Area}

Some notions were difficult to categorize as true or false. For example, the role of genetics in kidney damage: there might be a genetic predisposition, but that probably did not affect the pathogenesis.

"... and then I have to say that my mother also had a weak kidney. So it is also in the genes." (P6)

Other unclear items were whether kidney damage is caused by alcohol and organ abnormalities.

"I have always taken a stiff drink, and that can cause kidney damage." (P23)

Treatment with an infusion of water to flush the kidneys is unnecessary for CKD, but is very important for acute prerenal failure and protection against contrast agents.

\section{Coping with Anxiety}

A first reaction of patients being labeled with CKD was fear and doom-thinking about the future. To cope with fear, the participants gathered several signals to minimize seriousness. 


\section{Concerns}

Some participants were shocked when they received the results of their blood tests. They worried and imagined dialysis or kidney transplantation. Follow-up was stressful to them.

"My kidney function was not good. It was only $60 \%$ or so. So yes, that was certainly scary, and I did worry about it for a while." (P10)

\section{Lack of Relevance}

The anxiety at the time of diagnosis contrasted sharply with the perception that CKD is not a serious condition. Doubts about the importance of the diagnosis increased over time. One patient even refused to be labeled as having CKD. Other participants had no symptoms related to the decline of renal function, so it was difficult to imagine that the CKD was serious.

"Yes, I have no trouble with it, so I will not worry about it." (P11)

The participants' perceptions were influenced by the fact that the physicians seemed unconcerned about the diagnosis: they trivialized patients' concerns verbally, judged a referral to a nephrologist unnecessary, or did not explicitly treat the CKD.

"You think that it is not that important. It is stable, so that is good, and now and then it must be checked. Something like that." (P9)

The interviewees paid little attention to CKD and the physicians' explanation about it. This led to thoughts of a lack of relevance and priority.

"So then I saw another doctor, who did not talk about kidneys at all. So I assume that they are okay." (P25)

Some participants recognized their own responsibility regarding $\mathrm{CKD}$. They admitted that they neglected their CKD by not seeking further information.

"And I did not ask anything else about it, because, well, if it does not yet exist, I do not have to know about it!" (P19)

\section{Prerequisites for Self-Management}

Participants mentioned 2 factors that are important for living a healthier life: knowledge about the potential effects of lifestyle on CKD and willingness to change. These factors are strongly connected to each other and both are required to actually change lifestyle.

\section{Lifestyle Literacy}

Various lifestyle interventions for preventing cardiovascular events and kidney deterioration were mentioned during the interviews: weight control, smoking cessation, sodium restriction, physical exercise, and preventing dehydration. The participants knew about lifestyle in relation to their hypertension or diabetes, but did not realize the positive effects of lifestyle changes on kidney function.

"I do realize that my blood pressure is too high, that I haven't got my cholesterol right, that I am overweight, that I have to keep working on it and pay attention to it all. But I never made the connection that it affects the kidneys." (P17)

\section{Willingness to Change}

Notions about lifestyle changes differed among the participants. Most were motivated to adjust their lifestyle, but 1 patient argued:

"... it is all very well for them to say that it is this way and you must do such and such. But people do not do it. And I do not either. And that is why I say it does not help." (P23)

A proactive attitude toward renal decline and medication problems was also discussed. Behavior varied from taking total control to waiting for the doctor to come along.

"As soon as it is under 40 again, I will make it clear that something's wrong or ask for a consultation." (P19)

\section{Reciprocity in Information Provision}

Patients gathered CKD knowledge from various professionals and had different views on the tasks of professionals involved in CKD care. Patients indicated that it helps when information comes with empathy and is tailored to patients' personal needs.

\section{Information Sources}

Many medical coworkers were involved in informing patients: physicians, their assistants, practice nurses, nephrologists, cardiologists, pharmacists, and even a physiotherapist. Most information was given verbally, although some participants received written information. The internet was the source that was preferred.

\section{Views on Professional Tasks}

There was a general satisfaction about the care received from the physicians and nurse practitioners, although doubts about their knowledge were reported. 


\section{Empathy}

Empathy from the physicians was important. The participants judged a friendly approach as very important. They wanted the physicians to accept their treatment preferences and provide timely information. One patient did not feel free to ask questions:

"I myself know nothing and it scares me a little. He told me that my kidney function was not all that great. Then I am someone who does not open his mouth, yes. " (P10)

\section{Tailored Information}

The participants reported knowledge deficits. Not all felt well informed and reported that physicians did not spend enough time on detailed explanation. Other participants could not remember the information.

"The doctor has neither the time nor the energy to explain it that way." (P16)

"I was informed, but not well informed." (P20)

A number of questions remained. For example, it was confusing for patients to find that CKD has several synonyms that were used interchangeably: "renal impairment" and "kidney failure." The interviewees wondered about the difference. Patients expected their physicians to tailor the information.

"We do not want too many medical terms because we do not understand them. It is never been my field of work." (P1)

\section{Discussion}

\section{Summary of Main Findings}

Four main themes emerged from the interviews: CKD literacy, coping with anxiety, prerequisites for self-management, and reciprocity in information provision. Patients had deficiencies in their CKD knowledge so that misconceptions arose about causes, symptoms, and prognosis. There was a discrepancy between the anxiety at diagnosis and the later feeling of irrelevance of CKD. Lack of CKD symptoms and physicians' attitudes reduced the sense of seriousness. The patients failed to associate lifestyle and cardiovascular disease with CKD. Some were willing to make lifestyle changes. Not all were well informed about the consequences that CKD might have. The participants express the need for tailored information.

\section{Comparison with Existing Literature}

Several qualitative and quantitative studies ${ }^{6,12,13}$ found that patients have little objective and per- ceived knowledge in all stages of CKD. This is in line with our study. We were surprised that there were so many misconceptions about CKD—why and when do misconceptions arise? Some studies show the health care professionals' difficulties with CKD management and education. ${ }^{16,17}$ Limited professional knowledge and lack of prioritization ${ }^{18}$ may contribute to knowledge gaps and misconceptions. Furthermore, our study uncovered problems at the level of the doctor-patient communication. The information physicians provide needs improvement. The current literature shows a low baseline understanding of kidneys and $\mathrm{CKD}^{19}$ among patients. The lack of understandable and uniform CKD information may be a contributing factor. ${ }^{20}$ Other studies report that patients remember little of what they have been told. ${ }^{21}$

It is questionable whether patients are ready to learn when they receive signals that make them doubt the severity of CKD. The participants stated that physicians not talking much about CKD is one such signal. Other signals were judging a referral to a nephrologist unnecessary and seeming not to actually treat the CKD. The lack of symptoms is another signal for patients that CKD is not a serious condition. These signals form what we call the "relevance discrepancy." The participants were worried at time of diagnosis, but later they trivialized their disease. Anxious patients avoid information gathering, consciously or unconsciously. Another study described this same phenomenon among patients with progressive renal failure in regard to education about transplantation and donation. ${ }^{22}$

Other researchers have identified themes that should be assessed in self-management interventions. ${ }^{23}$ We confirm that, from the patients' perspectives, disease-specific knowledge is one of the crucial themes. Contantini and colleagues ${ }^{24}$ describe the need for disease-specific information, tailored and focused on the situation of the individual patient. Our findings are consistent with this research. It seems obvious, but given the findings in our study, disease-specific information remains an important point that demands attention.

\section{Strengths and Limitations}

It is a strength that CvD and MD established internal validity with independent coding, used Atlas.ti, and conducted mind-mapping sessions with the research team in which additional perspectives 
and interpretation of analysis and findings were discussed. The iterative approach of the interviews and the interim data analysis assured the rigor of the data. Another strength is that we included patients with heterogeneous characteristics to collect a broad range of knowledge, feelings, and experiences. These broad outcomes enabled us to take conclusions for this specific population. A limitation is that we did not interview patients with African, Asian, or Latin origin. We cannot comment on how patients with non-white origin experience and understand CKD and the impact on lifestyle. Given the clear outcomes in our white population, we cannot exclude that the problems we found also occur in the non-white population. It is important to do additional research on this. All interviews took place in Dutch. We tried to limit the loss of nuance by having a native-English speaker translate representative quotations. One interviewer did all the interviews; we tried to lower the risk of interview bias by providing feedback on the interview style. We asked physicians to recruit informed patients. The study could be biased toward inclusion of better-informed patients, but the results show that these potentially well-informed patients also have knowledge caps, misconceptions, or are not able to link CKD to lifestyle changes.

\section{Implications for Practice}

The patients lack information about the cause, symptoms, and treatment of CKD. Clear information can reduce the occurrence of misconceptions. The patients do not recognize the link between CKD and cardiovascular risk and lifestyle. It is important to include CKD in cardiovascular information and link lifestyle changes to their positive effects on both cardiovascular disease and CKD. This link might increase patient willingness to make lifestyle changes. Practice nurses can provide important help in this process. ${ }^{25}$ Repeating the message without dilution helps encourage a healthier lifestyle and makes patients realize how to influence CKD. Patients want tailored information. To deliver tailored information, there is a need for providers to be aware of patients' perspectives about CKD first, not only at diagnosis, but also during treatment. Uniform patient information on the internet or in an article is helpful and useful.

\section{Conclusion}

Patients' knowledge of CKD is deficient. There is a discrepancy between the patients' concerned attitude at time of diagnosis and their sense of irrelevance later in the disease. Physicians should be aware that they, often unknowingly, deliver the wrong signals about the severity of CKD, which influences patient behavior toward lifestyle and willingness to enhance self-management. If physicians want to provide tailored and patient-centered information, they need to be aware that misconceptions and perceptions of CKD should be actively identified and addressed.

We thank all the participating CKD patients for their contribution.

To see this article online, please go to: http://jabfm.org/content/ 31/4/570.full.

\section{References}

1. Kidney Disease: Improving Global Outcomes (KDIGO) CKD work group. KDIGO 2012 clinical practice guideline for the evaluation and management of chronic kidney disease. Kidney Int Suppl 2013;3:1-150.

2. Coresh J, Selvin E, Stevens LA, et al. Prevalence of chronic kidney disease in the United States. JAMA 2007;298:2038-47.

3. Hibbard JH, Stockard J, Mahoney ER, Tusler M. Development of the Patient Activation Measure (PAM): conceptualizing and measuring activation in patients and consumers. Health Serv Res 2004;39: 1005-26.

4. Greer RC, Crews DC, Boulware LE. Challenges perceived by primary care providers to educating patients about chronic kidney disease. J Ren Care 2012;38:174-81.

5. McIntyre NJ, Fluck R, McIntyre C, Taal M. Treatment needs and diagnosis awareness in primary care patients with chronic kidney disease. Br J Gen Pract 2012;62:e227-32.

6. Plantinga LC, Boulware LE, Coresh J, Stevens LA, Miller ER, 3rd, Saran R, et al. Patient awareness of chronic kidney disease: trends and predictors. Arch Intern Med 2008;168:2268-75.

7. Chow WL, Joshi VD, Tin AS, et al. Limited knowledge of chronic kidney disease among primary care patients-a cross-sectional survey. BMC Nephrol 2012;13:54.

8. Wright Nunes JA, Wallston KA, Eden SK, Shintani AK, Ikizler TA, Cavanaugh KL. Associations among perceived and objective disease knowledge and satisfaction with physician communication in patients with chronic kidney disease. Kidney Int 2011;80: 1344-51. 
9. Schell JO, Patel UD, Steinhauser KE, Ammarell N, Tulsky JA. Discussions of the kidney disease trajectory by elderly patients and nephrologists: a qualitative study. Am J Kidney Dis 2012;59:495-503.

10. Tong A, Sainsbury P, Chadban S, et al. Patients' experiences and perspectives of living with CKD. Am J Kidney Dis 2009;53:689-700.

11. Tong A, Sainsbury P, Craig J. Consolidated criteria for reporting qualitative research (COREQ): a 32item checklist for interviews and focus groups. Int J Qual Health Care 2007;19:349-57.

12. Van Weel C. Validating long term morbidity recording. J Epidemiol Community Health 1995;49: 29-32.

13. van Weel C. Longitudinal research and data collection in primary care. Ann Fam Med 2005;3:S46-51.

14. Walker D, Myrick F. Grounded theory: an exploration of process and procedure. Qual Health Res 2006;16:547-59.

15. Marshall MN. Sampling for qualitative research. Fam Pract 1996;13:522-5.

16. Abdel-Kader K, Greer RC, Boulware LE, Unruh ML. Primary care physicians' familiarity, beliefs, and perceived barriers to practice guidelines in non-diabetic CKD: a survey study. BMC Nephrol 2014;15:64.

17. Greer RC, Ameling JM, Cavanaugh KL, et al. Specialist and primary care physicians' views on barriers to adequate preparation of patients for renal replacement therapy: a qualitative study. BMC Nephrol 2015;16:37.
18. van Dipten C, van Berkel S, de Grauw WJ, et al. General practitioners' perspectives on management of early-stage chronic kidney disease: a focus group study Submitted. Accepted for publication, BMC Fam Pract, 17 April 2018.

19. Fraser SD, Roderick PJ, Casey M, Taal MW, Yuen HM, Nutbeam D. Prevalence and associations of limited health literacy in chronic kidney disease: a systematic review. Nephrol Dial Transplant 2013; 28:129-37.

20. Tuot DS, Davis E, Velasquez A, Banerjee T, Powe NR. Assessment of printed patient-educational materials for chronic kidney disease. Am J Nephrol 2013;38:184-94.

21. Kessels RP. Patients' memory for medical information. J R Soc Med 2003;96:219-22.

22. Boulware LE, Hill-Briggs F, Kraus ES, et al. Identifying and addressing barriers to African American and non-African American families' discussions about preemptive living related kidney transplantation. Prog Transplant 2011;21:97-104.

23. Havas K, Bonner A, Douglas C. Self-management support for people with chronic kidney disease: patient perspectives. J Ren Care 2016;42:7-14.

24. Costantini L, Beanlands H, McCay E, Cattran D, Hladunewich M, Francis D. The self-management experience of people with mild to moderate chronic kidney disease. Nephrol Nurs J 2008;35:147-55.

25. Scherpbier-de Haan ND, Vervoort GM, van Weel C, et al. Effect of shared care on blood pressure in patients with chronic kidney disease: a cluster randomised controlled trial. Br J Gen Pract 2013;63: e798-806. 


\section{Appendix A. Interview guide}

(This interview guide was used as memory support for the interviewer, it was not a questionnaire for the participants)

First adjustments in blue

Second adjustments in red

Third adjustments in green

How were you informed about the diagnosis?

- How did you or your doctor find out that you have chronic kidney disease?

- When was it discovered?

- Who discovered it?

- What information did your doctor give you?

- Was the information clear?

- What were your thoughts when you heard that you have chronic kidney disease?

- Are you worried? Why or why not? How can doctors reassure you?

\section{What do you know about chronic kidney disease?}

- What do you know about kidney function and anatomy?

- What do you know about your own kidney function?

- What do you know about kidney failure? (Things such as causes, diagnosis, consequences, relation to cardiovascular diseases and diabetes, and prognosis.)

- Do you also have other illnesses? Do you know if there is a relationship between other illnesses and chronic kidney disease?

- Do you lack certain information? What additional information do you need?

What are the consequences of chronic kidney disease for you?

- Physical (any symptoms?)

- Social (does the disease limit you?)

- Psychological (thoughts or anxiety?)

- If you have no symptoms, do you know what symptoms indicate chronic kidney disease? Do you wish to receive this information?

How are you counseled?

- Please describe your treatment for your chronic kidney disease.

- Who advises you? How often? Do you have check-ups at the hospital? With whom?

- What is checked? Why is this important?

- What do you think of the follow-up? Are you satisfied with it? Why of why not?

- What do you need from your family physician for your chronic kidney disease? 
What is the effect of chronic kidney disease on your medications?

- Do you use any medication? Which ones? Can any of your medicines can cause kidney damage?

- Are you aware that medications influence kidney function? Does your doctor tell you why your medication needs adjustments?

- What has your family physician (or nephrologist or nurse practitioner) told you about medication in relation to kidney function?

- Was it comprehensible? What did you think then?

- Do you have a need for more information about medication and chronic kidney disease? From whom? In what form - email, printed information, personal explanation, etc.?

- What is the role of the pharmacist in providing information?

\section{What preventive actions are possible?}

- What do you do to prevent deterioration to end-stage renal failure?

- Have weight loss, sodium intake, smoking cessation, and other such subjects been discussed with you? If so, who discussed it with you? If not, do you need information about preventive actions?

- What do you think about lifestyle changes? Are they feasible?

- From whom and how would you like to get this information?

Could you provide a summary of the issues discussed? Are there important issues of interest which we have not named?

\section{Information needs}

- Do you feel that your family physician informed you well? If not, what do you still need? If you feel well informed: why?

- Imagine you are going to see your family physician tomorrow. What would you ask him/her about chronic kidney disease?

- From whom and when would you like to get what information? 


\section{Appendix B. Final thematic map}

\begin{tabular}{|c|c|c|}
\hline Category & Code name & Meaning of the code \\
\hline \multicolumn{3}{|l|}{ CKD Literacy } \\
\hline \multirow{34}{*}{$\begin{array}{l}\text { Knowledge } \\
\text { compatible } \\
\text { with } \\
\text { professional } \\
\text { standards }\end{array}$} & $\begin{array}{l}\text { The moment when the patient first knew there was } \\
\text { kidney damage }\end{array}$ & Awareness of the moment when kidney damage was ascertained varies \\
\hline & Blood pressure treatment & Treating blood pressure is part of the treatment for kidney damage \\
\hline & Periodic monitoring & Kidney damage is checked periodically \\
\hline & Treatment with medicines & The treatment of kidney damage is associated with taking medicines \\
\hline & Policy after diagnosis & $\begin{array}{l}\text { There are various degrees of knowledge about the policy for treating kidney damage after it has } \\
\text { been diagnosed }\end{array}$ \\
\hline & Effect of stress and smoking on blood pressure & Stress and smoking contribute to high blood pressure \\
\hline & Diagnosis by blood testing & You can determine kidney damage by blood testing \\
\hline & Diagnosis by urine testing & You can determine kidney damage by urine testing \\
\hline & Interpretation of lab results & Knowledge about how to interpret lab results varies \\
\hline & Position of the kidneys & The kidney are localized near the back \\
\hline & Indications for dialysis & Kidney dialysis is necessary if the kidneys no longer function \\
\hline & Association of kidney damage and dialysis & An association is made between kidney damage and dialysis \\
\hline & Sufficiency of one kidney & You can live with only one kidney \\
\hline & Purpose of kidneys & Kidneys purify your body and blood \\
\hline & Ignorance of what kidneys do & Some patients do not know what the function of the kidneys is \\
\hline & Ignorance of consequences of kidney damage & Some patients are unaware of the potential consequences of kidney damage \\
\hline & $\begin{array}{l}\text { Relation of kidney damage to heart disease and } \\
\text { death }\end{array}$ & Kidney damage can lead to earlier death as well as to heart disease \\
\hline & NSAIDs & You cannot take NSAIDS if you have kidney damage \\
\hline & Other nephrotoxic medications & $\begin{array}{l}\text { Allopurinol, Plaquenil, Sevikar, antihypertensive drugs, prednisone, and lisinopril are bad for the } \\
\text { kidneys }\end{array}$ \\
\hline & $\begin{array}{l}\text { Necessary medication adjustment and/or } \\
\text { assessment }\end{array}$ & The knowledge that kidney damage may be a reason for adjusting medication varies \\
\hline & Association of kidney damage and gout & Kidney damage and gout occur together \\
\hline & Association of kidney damage and contrast agents & If you have kidney damage, you must be careful with contrast agents for scans \\
\hline & Association of kidney function and pregnancy & Extra check-ups are necessary during pregnancy if you have kidney damage \\
\hline & Symptoms not connected to kidney damage & Some symptoms have nothing to do with kidney damage \\
\hline & No symptoms for kidney damage & Kidney damage does not cause any symptoms \\
\hline & Itch from kidney damage & Kidney damage can make you itchy \\
\hline & Tiredness from kidney damage & Kidney damage can make you tired \\
\hline & Kidney damage from dehydration & Kidney damage results from a shortage of fluids \\
\hline & Kidney damage from medication & Kidney damage results from the use of certain medications \\
\hline & Kidney damage from cancer or cancer therapy & Cancer or cancer treatment has something to do with kidney damage \\
\hline & Unknown cause & We do not know how kidney damage originates \\
\hline & Kidney damage from high blood pressure & Kidney damage results from high blood pressure \\
\hline & Kidney damage from diabetes & Kidney damage results from diabetes \\
\hline & Kidney damage from old age & Kidney damage can arise from old age \\
\hline \multirow{17}{*}{ Misconceptions } & Cure for kidney damage & Kidney damage is reversible and therefore can be cured \\
\hline & Kidneys on the side of the abdomen & The kidney are localized on the abdominal side of the body \\
\hline & Wandering kidney & The patient was told that he/she has a wandering kidney, but doesn't know what this means \\
\hline & Diagnosis via diagnostic imaging & You identify kidney damage with scans \\
\hline & Kidney damage from infectious diseases & Kidney damage arises from infection with a virus or bacteria in the workplace \\
\hline & Kidney damage from traumas & The physical trauma of an accident can cause kidney damage \\
\hline & Kidney damage from skin conditions & Psoriasis can cause kidney damage \\
\hline & Kidney damage from nerves & Stress can cause kidney damage \\
\hline & Kidney damage from anesthesia & Kidney damage arise from anesthesia in the past \\
\hline & Infections from kidney damage & If you have kidney damage, you can get infections \\
\hline & Pain from kidney damage & Kidney damage can be painful \\
\hline & $\begin{array}{l}\text { Symptoms of the musculoskeletal system from } \\
\text { kidney damage }\end{array}$ & Kidney damage can give you back pain and acidify your muscles \\
\hline & $\begin{array}{l}\text { Symptoms in fluid management from kidney } \\
\text { damage }\end{array}$ & You can retain more fluids if you have kidney damage \\
\hline & Urination problems from kidney damage & If you have kidney damage, it is more difficult to urinate \\
\hline & Light-colored urine & You can read your health from your urine: a light color means healthy kidneys \\
\hline & Cinnamon for kidneys & Cinnamon is good for the kidneys \\
\hline & Salt and cholesterol & Salt has an effect on cholesterol \\
\hline \multirow{7}{*}{ Gray area } & Homeopathy for lowering blood pressure & Alternative medicine is good for kidney function \\
\hline & Kidney damage and comorbidity & There are various ideas about the association of kidney damage with the intestines and lungs \\
\hline & Thoughts about the effect of salt & Salt makes the kidneys work harder, and too little salt leads to symptoms \\
\hline & Infusion for rinsing kidneys & $\begin{array}{l}\text { It has been discovered that an infusion (drip) is a necessary treatment once chronic kidney } \\
\text { disease has been identified }\end{array}$ \\
\hline & Congenital or inherited kidney damage & Kidney damage is congenital or inherited \\
\hline & Kidney damage from alcohol & Alcohol causes kidney damage \\
\hline & Kidney damage from organ abnormalities & $\begin{array}{l}\text { Organ abnormalities such as a kink in the ureter or an abnormality of the bladder can cause } \\
\text { kidney damage }\end{array}$ \\
\hline Imagining CKD & The overall picture of kidney damage & $\begin{array}{l}\text { There are different ideas about what kidney damage is: a chipped old cup, a number, a } \\
\text { shriveling up, holes in the kidneys, problems with excretion or blood poisoning, a comparison } \\
\text { with alveoli, a shortage of certain substances }\end{array}$ \\
\hline
\end{tabular}




\section{Appendix B. Continued}

\begin{tabular}{|c|c|c|}
\hline \multicolumn{3}{|c|}{ Coping with anxiety } \\
\hline \multirow[t]{6}{*}{ Concerns } & Fear of kidney replacement therapies & There is a fear of dialysis and there is a fear of kidney transplantation \\
\hline & Devastating diagnosis & Receiving a diagnosis of kidney damage is devastating \\
\hline & Concern about kidney damage & There is concern about having kidney damage \\
\hline & Tension about check-ups & Patients can be tense about having their kidney function tested \\
\hline & The picture of kidney-replacing therapy & There are various ideas about what the therapy for replacing kidney function is \\
\hline & $\begin{array}{l}\text { A mind that is, or is not, occupied with kidney } \\
\text { damage }\end{array}$ & A patient may or may not spend time mulling over kidney damage \\
\hline \multirow[t]{15}{*}{$\begin{array}{l}\text { Lack of } \\
\text { relevance }\end{array}$} & The unimportance of what is not discussed & $\begin{array}{l}\text { Some patients conclude that if the doctor does not discuss kidney damage, then it can't be } \\
\text { important }\end{array}$ \\
\hline & Having kidney damage & Having kidney damage is not so bad \\
\hline & Doubting the diagnosis & The patient may doubt whether the diagnosis of chronic kidney damage is really applicable \\
\hline & $\begin{array}{l}\text { Influence of symptoms on thinking about kidney } \\
\text { damage }\end{array}$ & Having symptoms related to kidney damage makes you think about kidney damage a lot more \\
\hline & Low priority for kidney damage & There are more important things to discuss with the doctor than kidney damage \\
\hline & Limited monitoring: suggestive of limited gravity & $\begin{array}{l}\text { Limited monitoring makes the kidney damage seem less serious and vice versa: the more } \\
\text { monitoring, the more serious the kidney damage must be }\end{array}$ \\
\hline & Kidney damage: treatment only when it is serious & The degree of the kidney damage determines whether it is treated \\
\hline & $\begin{array}{l}\text { Treatment in primary care: suggestive of limited } \\
\text { gravity }\end{array}$ & $\begin{array}{l}\text { If the kidney damage is serious, in-hospital treatment is necessary. If the kidney damage is not } \\
\text { very serious, the family physician can treat it }\end{array}$ \\
\hline & Reassurance through communication & Doctors reassure patients by means of verbal and non-verbal communication \\
\hline & $\begin{array}{l}\text { The physician's and specialist's communication of } \\
\text { seriousness }\end{array}$ & $\begin{array}{l}\text { The physician and specialist do not get the message across that kidney damage is a serious } \\
\text { problem }\end{array}$ \\
\hline & Reassurance via monitoring & Referrals and monitoring affect the concern, anxiety, and reassurance of patients \\
\hline & Holding kidney damage at bay & $\begin{array}{l}\text { If you don't know the ins and outs of kidney damage, you can keep kidney damage at a distance } \\
\text { and stick your head in the sand }\end{array}$ \\
\hline & Unimpressive information & The information has made no impression, which is why the patient cannot reproduce it \\
\hline & Awareness due to interview & Taking part in the interview makes you reflect about kidney damage \\
\hline & Information unwanted as long as possible & $\begin{array}{l}\text { Sometimes a patient does not want to know until the kidney damage becomes so serious or has } \\
\text { such consequences that he/she must know }\end{array}$ \\
\hline \multicolumn{3}{|c|}{ Prerequisites for self-management } \\
\hline \multirow{9}{*}{$\begin{array}{l}\text { Lifestyle } \\
\text { literacy }\end{array}$} & Helplessness & There is nothing you yourself can do to stop the kidney damage from getting worse \\
\hline & Alcohol moderation & It is advisable to moderate the use of alcohol \\
\hline & Healthy eating & It is advisable to eat healthful food \\
\hline & Weight watching & It is advisable to keep your weight at a healthy level \\
\hline & As few pills as possible & It is preferable to use as few medications as possible \\
\hline & Smoking & Smoking is bad for your health \\
\hline & Enough exercise & It is advisable to get enough exercise \\
\hline & Enough water & It is advisable to drink enough water \\
\hline & Limited salt & It is advisable to eat as little salt as possible \\
\hline \multirow[t]{10}{*}{$\begin{array}{l}\text { Willingness to } \\
\text { change }\end{array}$} & Lifestyle advice & $\begin{array}{l}\text { The lifestyle advice given by the doctor or the nurse practitioner is carried out to varying } \\
\text { degrees }\end{array}$ \\
\hline & Preparedness to takes one's own responsibility & $\begin{array}{l}\text { Patients have different ideas about taking their own responsibility in de treatment of chronic } \\
\text { kidney damage }\end{array}$ \\
\hline & $\begin{array}{l}\text { Knowledge of the course of one's own kidney } \\
\text { function }\end{array}$ & What patients know about the course of their own kidney function varies \\
\hline & Informing the pharmacist oneself & You can inform the pharmacist yourself about your kidney function \\
\hline & $\begin{array}{l}\text { Patient taking over investigation of medication } \\
\text { nephrotoxicity }\end{array}$ & Finding out for yourself whether a medication is dangerous for the kidneys \\
\hline & Do-it-yourself treatment and prevention & After receiving advice, the patient him/herself makes decisions about treatment and prevention \\
\hline & $\begin{array}{l}\text { The patient's own plan for taking possibly } \\
\text { nephrotoxic medicine }\end{array}$ & The patient him/herself decides whether or not to take potentially harmful medicine \\
\hline & A wish to involve one's partner in the policy & It's nice to be able to discuss it with each other and make decisions together. \\
\hline & The doctor who knows best & The doctor knows best what should be done; you take that for granted \\
\hline & Influence of trust in the treating professional & Trusting the treating professional influences the degree to which treatment advice is taken \\
\hline \multicolumn{3}{|c|}{ Reciprocity in information provision } \\
\hline \multirow{16}{*}{$\begin{array}{l}\text { Information } \\
\text { sources }\end{array}$} & Information from the pharmacy & Information about kidney damage that the pharmacy gives \\
\hline & $\begin{array}{l}\text { Information from the package insert for the } \\
\text { medicine }\end{array}$ & Information about kidney damage from the package insert for the medicine \\
\hline & Information from books & Information about kidney damage from books \\
\hline & Information from the cardiologist & Information about kidney damage received from the cardiologist \\
\hline & Information from the practice assistant & Information about kidney damage received from the practice assistant \\
\hline & Information from the internet & Information about kidney damage from the internet \\
\hline & Information from the internist & Information about kidney damage received from the Internist \\
\hline & Information from the physiotherapist & Information about kidney damage received from the physiotherapist \\
\hline & Information from the family physician & Information about kidney damage received from the family physician \\
\hline & Information from one's surroundings & Information about kidney damage received from people in one's own circles \\
\hline & Information from the nurse practitioner & Information about kidney damage received from the nurse practitioner \\
\hline & Information from TV & Information about kidney damage seen on TV \\
\hline & Information from a printout of lab results & Information that is given with the aid of a printout of lab results \\
\hline & Verbal information & Information about kidney damage that is given to the patient verbally \\
\hline & Written information & Information about kidney damage that is given to the patient in writing \\
\hline & Information transmitted by telephone & Information about kidney damage that is given to the patient by telephone \\
\hline
\end{tabular}




\section{Appendix B. Continued}

\begin{tabular}{|c|c|c|}
\hline \multirow{18}{*}{$\begin{array}{l}\text { Views on } \\
\text { professional } \\
\text { tasks }\end{array}$} & Appreciation of the role of the family physician & $\begin{array}{l}\text { There are various evaluations of the role of the family physician with regard to the care for } \\
\text { kidney damage }\end{array}$ \\
\hline & Tasks of the family physician & What is and is not included in the tasks of the family physician concerning kidney damage \\
\hline & Role of the nurse practitioner & What is and is not included in the tasks of the nurse practitioner concerning kidney damage \\
\hline & Tasks of the specialist & What is and is not included in the tasks of the specialist concerning kidney damage \\
\hline & Appreciation of the role of the specialist & There are various evaluations of the role of the specialist concerning the care for kidney damage \\
\hline & Appreciation of the role of the dietician & There are various evaluations of the role of the dietician concerning the care for kidney damage \\
\hline & Cooperation of the physician and the pharmacy & Opinions differ about the cooperation of the physician and the pharmacy \\
\hline & Tasks of the pharmacist & What is and is not included in the tasks of the pharmacist concerning kidney damage \\
\hline & Added value of the pharmacist's explanations & Opinions differ about the added value of the pharmacist's explanations \\
\hline & Expertise: specialist versus family physician & Specialists are more expert than family physicians when it comes to kidney damage \\
\hline & Preference for treatment from the family physician & Sometimes there is a preference to have kidney damage treated by the family physician \\
\hline & The family physician's pharmacological knowledge & Impressions of the family physician's pharmacological knowledge vary \\
\hline & $\begin{array}{l}\text { Cooperation of healthcare professionals in the chain } \\
\text { of care }\end{array}$ & Patients do not notice much about the cooperation within the chain of care \\
\hline & Evaluation of the information in package inserts & Opinions differ about the added value of the information in package inserts \\
\hline & Evaluation of lab printouts & Opinions differ about the value the information provided in lab printouts \\
\hline & Generalized folders & Information in brochures is too general and focuses too little on the individual situation \\
\hline & Trust in kidney damage care & The degree of trust in kidney damage care varies \\
\hline & Extra costs & Patients are faced with extra costs when their kidney function must be repeatedly tested \\
\hline \multirow[t]{6}{*}{ Empathy } & Pleasant healthcare professionals & It is important to the patients that the healthcare professionals are interact pleasantly \\
\hline & Respect for treatment limits & Patients want doctors to respect their treatment limits \\
\hline & The opportunity to ask questions & Patients like to feel that they can always ask the doctor questions about kidney damage \\
\hline & Uneasiness about asking for a referral & $\begin{array}{l}\text { Patients can feel uncomfortable about asking for a referral to a specialist to have kidney damage } \\
\text { assessed }\end{array}$ \\
\hline & Timely notification & $\begin{array}{l}\text { Some patients have the feeling that they were informed about the kidney damage some time } \\
\text { after it had become known }\end{array}$ \\
\hline & Symptoms taken seriously & Patients want to feel that the doctor takes their symptoms seriously \\
\hline \multirow{6}{*}{$\begin{array}{l}\text { Tailored } \\
\text { information }\end{array}$} & Importance of repeating information & Repeating information is important \\
\hline & Importance of time for explanations & $\begin{array}{l}\text { Although they consider it important, patients feel that doctors often have too little time to give } \\
\text { explanations }\end{array}$ \\
\hline & Adequate and complete information & Adequate and complete information is important \\
\hline & Verbal information suited to the patient & Patients want the doctor to tailor the verbal information to the needs and ability of the patient \\
\hline & Feeling well informed & The feeling of being well informed by healthcare professionals varies among the patients \\
\hline & Difficulty with inconsistent terms for kidney damage & $\begin{array}{l}\text { Patient have difficulty with the many differing terms: kidney damage, kidney insufficiency, } \\
\text { creatinine, etc. }\end{array}$ \\
\hline
\end{tabular}

